\title{
USIA, PEKERJAAN, DAN JENIS PERSALINAN TERHADAP KEJADIAN PROLAP UTERI DI POLIKLINIK OBGIN RSUD Dr. SOEKARDJO TASIKMALAYA
}

\author{
Neni Nuraeni \\ Dosen Keperawatan FIK UMTAS Tasikmalaya \\ aeni_taurs@yahoo.com
}

\begin{abstract}
Abstrak.
Angka kejadian penyakit kandungan saat ini masih tinggi termasuk kejadian prolap uteri. Banyak faktor yang menyebabkan kejadian ini antara lain usia, paritas, jenis persalinan, pekerjaan, riwayat penyakit sebelumnya yang bila tidak ditangani akan mengakibatkan uterus keluar di introitus vagina yang menyebabkan infeksi karena ulkus serviks, hemoroid akibat konstipasi, dan obstruksi saluran urine.Tujuan penelitian mengetahui hubungan usia, pekerjaan, dan jenis persalinan dengan kejadian prolap uteri. Penelitian ini menggunakan penelitian deskripsi korelasional dengan pendekatan cross sectional. Populasi pada penelitian ini seluruh pasien yang berkunjung ke poli klinik Obgin RSUD dr. Soekardjo Kota Tasikmalaya dengan mengambilan sampel menggunakan tehnik sampel consecutive sampling yang dilakukan selama 2 minggu sebanyak 44 orang. Analisis data menggunakan uji chi square. Hasil penelitian menunjukkan faktor usia, pekerjaan dan jenis persalinan tidak ada hubungan dengan kejadian prolap uteri di poli Obgin RSUD dr. Soekardjo Tasikmalaya dengan $\rho$ value $>0,05$. Sebagai tenaga kesehatan harus memberikan informasi kepada masyarakat untuk menghindari faktor resiko kejadian prolap seperti obesitas, pekerjaan dengan mengangkat beban yang berat, ketika persalinan hindari mengedan yang berlebihan, dan batuk kronis.
\end{abstract}

Kata kunci: Prolap uteri, usia, pekerjaan, jenis persalinan

\begin{abstract}
Abcstract
Incidence of the current high prolap uteri.Many factors that causes this incident is age, parity, the delivery, work, and previous disease history. if not addressed will result in the uterus out in introitus vagina which led to infection as ulcer cervical, hemorrhoidal, and obstruction the research relations urine. This research using research description of correlational with the approach cross sectional. The population to research that all patients who visited clinics Obgin hospital dr. Soekardjo Tasikmalaya. Sample technique use consecutive sampling made during two weeks as many as 44 people. An analysis of data using the chi square. The result showed all factors the age, work and the delivery there was no relating to the prolap uteri, with $\rho$ value $>0,05$. As health workers should provide information to the public to avoid risk factors for prolap events such as obesity, work by lifting heavy burdens, when labor avoid excessive straining, and chronic cough.
\end{abstract}

Key words; Prolap Uteri, age, work, the delivey

\section{PENDAHULUAN}

Angka kejadian prolap uteri di Indonesia, selama tahun 2010 di ruang rawat ginekologi RSUP dr. Hasan Sadikin Bandung sebanyak 17 kasus. Data dari RS.Dr.Pingardi Medan dilaporkan bahwa dari 5.371 kasus ginekologi, kasus prolap uteri sebanyak 65 kasus, sedangkan data dari RS.M. Jamil padang selama lima tahun sebanyak 94 kasus. Data dari RS M.H Palembang dari tahun 1999-2003 dilaporkan kasus prolapsus uteri dari rekam medis pasien periode tahun 1999 tahun 2003 sebanyak 43 kasus terjadi 
pada usia 45-64 tahun (65\%) dan usia termuda adalah pada usia 30 tahun $(2,32 \%)$, grademultipara $(47 \%)$ dan prolapsus uteri grade III (77\%) (Anhar K, 2004; Medrek RSUP dr.Hasan Bandung, 2010; Widjarnarko, 2009). Di Negara Turki kejadian prolap uteri diperkirakan terjadi pada per 10.000-15.000 kelahiran (Cingillioglu \& Yildirim, 2010),sedangkan kejadian prolap uteri di Nepal sekitar 2063 orang, $50 \%$ terjadi pada wanita usia $20-24$ tahun, $14 \%$ terjadi sebelum usia 20 tahun dan $44 \%$ pada wanita sebelum usia 30 tahun (Shah, 2010).

Prolap uteri paling sering ditemukan pada wanita multipara sebagai akibat trauma pada otot- otot fasia pelvis ketika persalinan. Penyebab potensial adalah obesitas, asites dan tumor uterus atau ovarium. Batuk kronis, konstipasi, tidak adanya esterogen setelah menopouse dan kecenderungan genetik, lemahnya dasar panggul akibat kerusakan dasar panggul karena partus atau usia lanjut dan tekanan intra abdominal meninggi akibat asites, tumor intra abdomen dan batuk kronis tetapi juga karena adanya retinakulum uteri yang lemah akibat adanya asteni atau kelainan kongenital (Baradero \& Dayrit ,2007; Mayer \& Munder,2005).

Hasil studi pendahuluan didapatkan angka kunjungan pasien dengan prolap uteri di Poliklinik obgin RSUD dr. Soekardjo Kota Tasikmalaya periode JanuariNopember 2011 rata-rata perbulan 22 orang. Usia pasien sekitar 60 lebih, paritas rata-rata lebih dari 3 kali melahirkan dengan jenis persalinan kebanyakan spontan. Pekerjaan rata-rata ibu rumah tangga.Dari hasil wawancara didapatkan bahwa mereka rata-rata mengerjakan pekerjaan rumah yang dikatakan tidak ringan bahkan ketika hamilpun masih mengerjakan pekerjaan rumah yang berat seperti mengangkat beban yang terlalu berat. Oleh karena itu, peneliti ingin mencari hubungan usia, pekerjaan dan jenis persalinan terhadap kejadian prolap uteri di Poli Obgyn RSUD Dr. Soekarjdo Tasikmalaya.

\section{TINJAUAN TEORI}

Prolap uteri adalah penonjolan dari tubuh dan atau satu atau adanya penyusupan uterus melewati serviks, vulva, dan Vagina (Bodner\& Shrivastava, 2007; Mouritsen, 2005; dan Reeder, Martin \& Griffin , 2011). Prolap uteri terjadi bila otot dan ligamentum dasar panggul sangat teregang terutama akibat persalinan lama atau usia tua (umumnya prolapsus terjadi pada usia diatas 55 tahun anatara lain obesitas, keganasan uterus, diabetes mellitus, bronchitis chronis, asma, pekerjaan mengangkat beban yang berat terutama bila otot panggul sudah melemah atau uterus retroversio, dan tumor uterus atau ovarium yang besar (Widjanarko, 2009; Reeder, Martin \& Griffin, 2011).

Prolap uteri paling sering ditemukan pada wanita multipara sebagai akibat trauma pada otot- otot fasia pelvis ketika persalinan. Penyebab potensial adalah obesitas, asites dan tumor uterus atau ovarium. Batuk kronis, konstipasi, tidak adanya esterogen setelah menopouse dan kecenderungan genetik juga menunjang timbulnya prolap uteri, lemahnya dasar panggul akibat kerusakan dasar panggul karena partus atau usia lanjut dan tekanan intra abdominal meninggi akibat asites, tumor intra abdomen dan batuk kronis tetapi juga karena adanya retinakulum uteri yang lemah akibat adanya asteni atau kelainan kongenital.

Lazarou, Scotti et al (2010) dan Onwude (2011), mengemukakan bahwa perjalanan penyakit prolap uteri terdapat dalam berbagai tingkat, dari yang paling ringan sampai prolapsus uteri totalis. Hal ini diakibatkan karena persalinan, khususnya persalinan pervaginam yang susah dan terdapatnya kelemahankelemahan ligament yang tergolong dalam fasia endopelviks dan otot-otot serta fasiafasia dasar panggul. Keadaan tekanan intraabdominal yang meningkat dan kronik juga akan memudahkan penurunan uterus, terutama apabila tonus otot-otot mengurang seperti pada penderita dalam 
masa menopause. Serviks uteri yang sudah keluar di vagina,akan tergeser oleh pakaian wanita sehingga lambat laun menimbulkan ulkus yang dinamakan ulkus serviks.

Jika fasia di bagian depan dinding vagina kendor biasanya trauma obstetric, uterus akan terdorong oleh kandung kencing sehingga menyebabkan penonjolan dinding depan vagina kebelakang yang dinamakan sistokel. Sistokel yang pada mulanya hanya ringan saja, dapat menjadi besar karena persalinan berikutnya yang kurang lancar, atau yang diselesaikan dalam penurunan dan menyebabkan urethrokel. Urethrokel harus dibedakan dari divertikulum urethra. Pada divertikulum keadaan urethra dan kandung kencing normal hanya dibelakang urethra ada lubang yang membuat kantong antara urethra dan vagina.kekendoran fasia dibagian belakang dinding vagina oleh trauma obstetric atau sebab-sebab lain dapat menyebabkan turunnya rectum kedepan dan menyebabkan dinding belakang vagina menonjol kelumen vagina yang dinamakan retrokel. Enterokel adalah hernia dari kavum Douglasi. Dinding vagina bagian belakang turun dan menonjol ke depan. Kantong hernia ini dapat berisi usus atau omentum.

Reeder, Martin \& Griffin (2011), bahwa gejala prolaps uteri meliputi rasa berat pada panggul, nyeri punggung bawah, ketidaknyamanan abdomen bawah, dispareunia, dan merasa ada sesuatu yang keluar. Pada kasus berat, wanita dapat merasakan adanya massa tepat di dalam vagina atau introitus. Kompresi dan distorsi kandung kemih menyebabkan residu urine yang disertai inkontinentia atau infeksi saluran kemih.

Bodner \& Shrivastava (2007) melaporkan dari hasil penelitiannya semua wanita yang mengalami prolap uteri di Nepal ditandai dengan adanya nyeri saat berhubungan, nyeri pada daerah abdomen, nyeri pada pinggang, kesulitan defekasi, keputihan, rasa terbakar saat berkemih dan kesulitan saat berjalan, duduk dan berdiri karena merasa tidak nyaman adanya benjolan yang mengganjal di daerah kemaluan. Ravindran, Savitri dan Bhavani (2009) melaporkan bahwa wanita di Tamil Nadu India merasakan adanya sesuatu yang keluar dari kemaluan, nyeri pinggang, penurunan sensasi, nyeri abdominal, gangguan berkemih, frekuensi dan nyeri saat berkemih, stress inkontinentia, kesulitan defekasi, adanya perdarahan sedikit-sedikit dan adanya rasa mengganjal saat berjalan dan mengangkat barang.

\section{METODE PENELITIAN}

Jenis penelitian yang digunakan deskripsi korelasional dengan pendekatan cross sectional. Populasi pada penelitian ini seluruh pasien yang berkunjung ke poliklinik Obgin RSUD dr. Soekardjo Kota Tasikmalaya sebanyak 212 orang dengan mengambilan sampel menggunakan tehnik sampel consecutive sampling yang dilakukan selama 2 minggu. Variabel penelitian terdiri dari variabel bebas yaitu usia, pekerjaan, dan jenis persalinan sebelumnya. Variabel terikat adalah kejadian prolap uteri. Pengumpulan data dilakukan melalui kuesioner yang sebelumnya dilakukan uji validitas dan realibilitas. Proses pengolahan data melalui tahap-tahap Editing, Coding, tabulating, dan entry data, dengan uji satistik yang digunakan Uji Chi Square.

\section{HASIL PENELITIAN}

Hasil penelitian sebagi berikut:

1. Hubungan usia dengan kejadian prolap uteri di Poliklinik Obgin RSUD dr. Soekardjo Kota Tasikmalaya

Pada tabel 1. menunjukkan bahwa $39 \%$ kejadian prolap uteri pada usia dewasa tua (41-65 tahun), namun secara uji bivariat tidak ada hubungan antara usia dengan kejadian prolap uteri. 
Tabel 1. Hubungan usia dengan kejadian prolap uteri

\begin{tabular}{lccc}
\hline \multirow{2}{*}{$\begin{array}{c}\text { Usia } \\
\text { Dewasa }\end{array}$} & \multicolumn{2}{c}{$\begin{array}{c}\text { Kejadian Prolap } \\
\text { Uteri }\end{array}$} & Jumlah \\
\cline { 2 - 3 } & Ya & Tidak & \\
\hline Muda & 2 & 7 & 9 \\
\hline Tengah & 3 & 14 & 17 \\
\hline Tua & 7 & 11 & 17 \\
\hline Jumlah & 12 & 32 & 44 \\
\hline$\rho=0,334$ & & &
\end{tabular}

2. Hubungan pekerjaan dengan kejadian prolap uteri di Poliklinik Obgin RSUD dr. Soekardjo Kota Tasikmalaya

Tabel 2. Hubungan antara pekerjaan dengan kejadian prolap uteri

\begin{tabular}{lccc}
\hline \multirow{2}{*}{ Pekerjaan } & \multicolumn{3}{c}{ Kejadian Prolap } \\
& Ya & Tidak & \\
\cline { 2 - 3 } & 11 & 26 & 37 \\
\hline Bekerja & 1 & 6 & 7 \\
\hline Tldak & 12 & 32 & 44 \\
\hline Jumlah & 12 & \\
\hline$\rho=0,653$ & & &
\end{tabular}

Tabel 2 menunjukkan bahwa responden yang bekerja $30 \%$ mengalami prolap uteri, namun secara uji bivariat tidak ada hubungan antara pekerjaan dengan kejadian prolap uteri.

3. Hubungan antara jenis persalinan yang pernah dilakukan dengan kejadian prolap uteri di Poliklinik Obgin RSU Kota Tasikmalaya

Tabel 3. Hubungan jenis persalinan dengan kejadian prolap uteri

\begin{tabular}{|c|c|c|c|}
\hline \multirow{2}{*}{$\begin{array}{c}\text { Jenis } \\
\text { persalinan }\end{array}$} & \multicolumn{2}{|c|}{$\begin{array}{c}\text { Kejadian Prolap } \\
\text { Uteri }\end{array}$} & \multirow{2}{*}{ Jumlah } \\
\hline & Ya & Tidak & \\
\hline $\begin{array}{l}\text { Spontan, } \\
\text { vakum, forcep }\end{array}$ & 11 & 31 & 42 \\
\hline Belum pernah & 1 & 1 & 2 \\
\hline Jumlah & 12 & 32 & 44 \\
\hline
\end{tabular}

Tabel 3. Jenis persalinan responden $26 \%$ mempunyai riwayat persalinan spontan, vakum dan forcep, namun tidak ada hubungan antara jenis persalinan yang pernah dilakukan dengan kejadian prolap uteri.

\section{PEMBAHASAN}

Penelitian ini didapatkan lebih banyak pasien yang mengalami prolap uteri pada usia lebih dari 55 tahun, karena usia 55 tahun mengalami kelemahan otot abdomen dan otot dasar panggul. Bila dilihat dari bekerja, hampir semua responden yang mengalami prolap bekerja dimana responden sebagai ibu rumah tangga tetapi dalam pekerjaannya banyak mengangkat beban berat seperti mengambil air dari sumur dengan tidak memikirkan posisi tubuh dalam mengangkat barang. Demikian pula bila dilihat dari jenis persalinan yang pernah dialami kebanyakan respon spontan, vakum dan forcep. Dimana persalinan spontan akan mengakibatkan turunnya uterus karena mengedan yang kuat saat melahirkan.Walaupun demikian sebagian responden tidak mengalami prolap uteri sehingga tidak ditemukan hubungan antara usia, pekerjaan, dan jenis persalinan yang sebelumnya dengan kejadian prolap uteri.

Widjanarko (2009) dan Reeder, Martin \& Griffin (2011) mengemukakan bahwa prolap uteri terjadi bila otot dan ligamentum dasar panggul sangat teregang terutama akibat persalinan lama atau usia tua (umumnya prolapsus terjadi pada usia diatas 55 tahun anatara lain obesitas, keganasan uterus, diabetes mellitus, bronchitis chronis, asma, pekerjaan mengangkat beban yang berat terutama bila otot panggul sudah melemah atau uterus retroversio, dan tumor uterus atau ovarium yang besar

Demikian pula yang dikemukan oleh Mouritsen (2005), prolap uteri dihubungkan dengan pasien pernah mengalami pembedahan organ prolap sebelumnya, sebelumnya pernah mengalami 
colposuspensi, histerektomi, kegemukan, usia tua, konstipasi dan batuk kronik, kelemahan pada otot dasar panggul, paritas terutama pada multipara dan komplikasi kelahiran pervaginam, pekerjaan mengangkat beban yang berat, lebarnya diameter tulang pelvis dan kemungkinan terjadi pada menopouse dan menurunnya hormon esterogen.

\section{KESIMPULAN}

Hasil penelitian menunjukkan bahwa faktor usia, pekerjaan, dan jenis persalinan sebelumnya tidak berhubungan dengan kejadian prolap uteri di Poli Obgin RSUD Dr. Soekardjo Tasikmalaya

\section{SARAN}

Wanita yang mengalami prolap uteri biasanya terjadi pada Wanita dengan usia lebih dari 50 tahun, bekerja dan jenis persalinan yang sebelumnya yaitu spontan. Yang perlu disarankan kepada Wanita subur untuk menghindari faktor resiko kejadian prolap seperti obesitas, pekerjaan dengan mengangkat beban yang berat, ketika persalinan hindari mengedan yang berlebihan, dan batuk kronis.

\section{DAFTAR PUSTAKA}

Anhar, K., (2004). Kasus prolap uteri di Rumah Sakit dr. M Hoesni Palembang selama usia tahun 1999-2002. http://digilib.unsri.ac.id/download/Kasu s Prolapsus Uteri di Rumah Sakit Dr_Mohammad Hoesni.Pdf.

Bodner, \& Shrivastava, (2007). Risk factor for uterine prolapse in Nepal. International Urogynecology Journal 18:1343-1346.

http://www.springerlink.com/content/0 46m016356g62408/fulltext.pdf. di peroleh tanggal 5 Februari 2007.

Baradero, Dayrit, \& Siswadi., (2007). Klien gangguan sistem reproduksi dan seksualitas. Jakarta: EGC.
Lazaraou, Scotti, et al., (2010). Uterine prolapse. http://emedicine. medscape.com/article/264231overview. diperoleh tanggal 29 Maret 2010.

Mayer, B.H., \& Munder, J., (2005). Women'shealth: a guide to health promotion and disorder management. Lippincott: WIlliam and Wilkins.

Mouritsen, L., (2005). Classification and evaluation of prolapse best practice \& research clinic obstetric ang gynecology. Best practice \& research clinical obstetri and gynecology. Vol 19 No 6. http://www.urmc.rochester. edu/smd/gme/prospective/obgyn/docu ments/wk301MouritsenPOP.pdf. diperoleh bulan Agustus 2005.

Onwude, (2011). Genital prolapse in women. Journal of epidemiology and community health. http:// clinicalevidence.bmj.com/ceweb/condi tions/woh/0817/0817-Background jsp. diperoleh tanggal 30 November 2009.

Ravindran S., Savitri, \& Bhavani, (2009). Women's experiences of utero-vaginal prolapse: a qualitative study from Tamil Nadu India. http://www.ruwsec. org/uploads/41.pdf. diperoleh tanggal 4 November 2009.

Reeder, Martin, \& Griffin, (2011). Keperawatan maternitas; kesehatan wanita, bayi dan keluarga. Alih bahasa; Afiyanti, Nur Rachmawati dkk (2003/2011). Edisi 18. Volume 1. Jakarta: EGC.

Shah, P. (2010). Uterine prolapse and maternal mordibity in Nepal: a human rights imprative. http://www. springerlink.com/content/d10316t0266 37340/fulltext.pdf. diperoleh tanggal 21 Mei 2010.

Widjanarko, B. (2009). Prolap uteri. http://Obstetginekologi.com. 